https://doi.org/10.30910/turkjans.448392

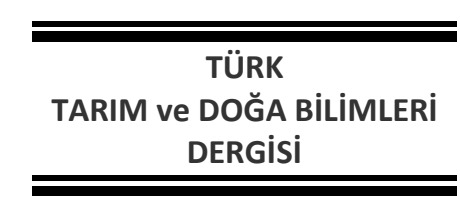

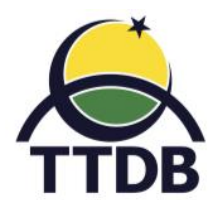

www.dergipark.gov.tr/turkjans

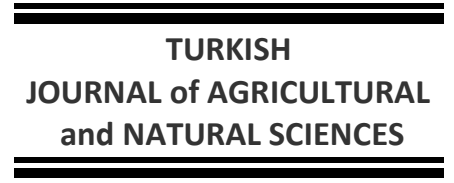

Araştırma Makalesi

\title{
Ordu ili Mısır Yetiştiriciliği Yapılan Alanlardaki Endoparazit Nematodlar Kök-ur Nematodu (Meloidogyne spp.) ile Kök Lezyon Nematod (Pratylenchus spp.)'larının Mevsimsel Populasyon Dalgalanması
}

\author{
Uğur YiĞiT, Faruk AKYAZI* \\ Ordu Üniversitesi, Ziraat Fakültesi Bitki Koruma Bölümü, 52200, ORDU \\ *Sorumlu yazar: farukakyazi@hotmail.com
}

Geliş Tarihi: 07.06.2018

Düzeltme Geliş Tarihi: 16.07.2018

Kabul Tarihi: 18.07.2018

Özet

Bu çalışma, bitkilerde ekonomik kayıplara neden olan iki önemli bitki paraziti nematodlar kök-ur nematodu (Meloidogyne spp.) ile kök-lezyon nematodu (Pratylenchus spp.)'nun mısır (Zea mays L.) yetiştiriciliği yapılan alanlardaki mevsimsel populasyon dalgalanmalarının belirlenmesini amaçlamaktadır. Ordu ilinde 20162017 yıllarında iki farklı mısır yetiştiriciliğinin yapıldığı alanlardaki (A ve B tarlası) toprak içerisinde bulunan kökur nematodu ikinci dönem larvaları $\left(\mathrm{J}_{2}\right)$ ile kök lezyon nematodlarına ait bireylerin populasyon dalgalanması yıl boyunca aylık periyotlarda takip edilmiştir. Çalışma sonucunda A tarlasında en yüksek populasyon yoğunluğu 2017 yılının Ekim ayında Meloidogyne spp. için 462 (J2/100 cm³ toprak) iken, Pratylenchus spp. için ise 38 (J2 /100 $\mathrm{cm}^{3}$ toprak) olarak tespit edilmiştir. B tarlasında yapılan sayımlarda ise en yüksek populasyon yoğunluğu Meloidogyne spp. için 2016 yılının Aralık ayında 203 (J2/100 cm³ toprak) gözlenirken, Pratylenchus spp. için Ağustos ayındaki yoğunluk 63 (nematod/100 $\mathrm{cm}^{3}$ toprak) olarak bulunmuştur. İki tarlada da kök ur nematodunun populasyon yoğunluğunda Sonbahar'a doğru belirgin artış gözlendiği, yaz aylarında ise yoğunluğun düşük seviyede devam ettiği gözlenmiştir. Kök lezyon nematodlarında ise populasyon yoğunluğu toprak sıcaklığı ile pozitif ilişki göstererek yıl boyunca belirli bir düzeyde artış gösterdiği tespit edilmiştir.

Anahtar kelimeler: Mısır, Meloidogyne spp., Pratylenchus spp., populasyon dalgalanması.

\section{Seasonal Population Fluctuations of Endoparasitic Nematodes in Maize Production Areas in Ordu Province of Turkey: Root-Knot Nematodes (Meloidogyne spp.) and Root Lesion Nematodes (Pratylenchus spp.)}

\begin{abstract}
This study aims to determine the seasonal population fluctuations of two important plant parasitic nematodes root-knot nematodes (Meloidogyne spp.) and root-lesion nematodes (Pratylenchus spp.) that causing economic losses in plants in the world in maize (Zea mays L.) growing areas. Population fluctuations of root-knot nematode infective second-stage larvae (J2) and root lesion nematode individuals (larvae+female) in soil were monitored monthly in two different maize growing fields (A and B) during 2016 and 2017 in Ordu province of Turkey. In the result of the study, the highest population were observed in October 2017 as 462 (J2/100 cm soil) $^{3}$ for Meloidogyne spp. and 38 individuals $/ 100 \mathrm{~cm}^{3}$ soil for Pratylenchus spp. at field A. The highest population of Meloidogyne spp. were observed as $203 \mathrm{~J} 2 / 100 \mathrm{~cm} 3$ soil in December 2016, while Pratylenchus spp. in August for 63 individuals $/ 100 \mathrm{~cm} 3$ soil at field B. In both fields, populations of root-knot nematodes in the soil were increased significantly in autumn months, but continued in low levels in summer. The root lesion nematodes population density showed a positive correlation with the soil temperature and increased at a certain level throughout the year.
\end{abstract}

Key words: Maize, Meloidogyne spp., Pratylenchus spp., population fluctuation. 


\section{Giriş}

Mısır (Zea mays L.), anavatanı Amerika kıtası olan binlerce yıldır üretimi yapılan, Antartika hariç dünyanın hemen her yerinde yetişebilen, tek yıllık sıcak iklim tahılıdır (Kün ve Emekliler, 1987; Anonim, 2005). Mısır, Dünya'da üretim miktarı bakımından ilk sırada yer alırken, ekilen alan bakımından ise buğday ve çeltikten sonra 3. sırada yer almaktadır. Dünyadaki toplam mısır üretimi 989 milyon ton olup bu üretimin yarısından fazlasını $A B D$ ve Çin üstlenmektedir. Üretimde bu iki ülkeyi Brezilya, Ukrayna, Arjantin, Hindistan, Meksika, Güney Afrika, Kanada ve Rusya takip etmektedir. Türkiye'de ise bu üretim 2016 yılı itibarı ile 6.800.192 dekarda 6.400.000 tondur (TÜiK, 2016). Ülkemizde bölge bazında en fazla mısır üretimi Akdeniz Bölgesi'nde yapılmaktadır. Tüm illerinde mısır üretimi yapılan Karadeniz Bölgesi ise bu üretime 227.812 ton mısır ile önemli bir katkı sağlamaktadır. Bölgemize iller bazında bakıldığında en fazla üretim Samsun'da yapılmakta olup bunu sırasıyla Amasya ve Tokat takip etmektedir (TÜiK, 2016).

Üretim alanı ve verim bakımından dünyada önemli kültür bitkilerinden olan mısırda hastalık, zararlı ve yabancı otlardan dolayı \%67 civarında ürün kayıpları meydana gelmektedir. Ürün kayıplarının \%13'ünün hastalıklardan, \%23'ünün yabancı otlardan ve \%31'inin ise bitki zararlılarından kaynaklandığı bildirilmiştir (Qerke ve ark., 1994). Bitki zararlılarının içerisinde mısırda zarara ve ürün kayıplarına yol açan bir grupta bitki paraziti nematodlardır. Nematodlar dünya üzerinde çok geniş bir yayılışa sahip olmasına rağmen, uzun yıllar çok az bilinen organizmalar grubu içerisinde yer almıştır. Bitki zararlısı nematodlara ait ilk çalışmalar, 19. yy'da kültür bitkilerinde yapmış oldukları zararların fark edilmesiyle başlamıştır (Thorne, 1961). Bundan sonraki aşamalarda yapılan çalışmalarda ise nematodların dünyada üç milyondan fazla bitkide hasara ve ürün kayıplarına neden olduğu belirlenmiştir (Koenning ve ark., 1999). Mısır üzerinde yapılan çalışmalar neticesinde ise 120 çeşit bitki paraziti nematod türü olduğu belirlenmiştir. Sadece Kuzey Amerika'da mısırda zararlı 60 dan fazla nematod türü tespit edilmiştir (Norton, 1983). Mısırda endoparazit nematodlar olarak Hoplolaimus (lance), Meloidogyne (rootknot), Pratylenchus (lesion) cinsine ait olanlar ile ektoparazit olarak Xiphinema (dagger), Longidorus (needle), Paratylenchus (pin), Helicotylenchus (spiral), Belonolaimus (sting), Paratrichodorus (stubby root), Criconemella (ring), ve Tylenchorhynchus (stunt) cinslerine dahil mısırda hasara neden olan nematodlar olarak iki şekilde bulunabilmektedirler (Tylka ve ark., 2011). Bu nematodların A.B.D'de yapılan bir araştırmaya göre mısırda \% 20 den fazla ürün kaybına neden olduğu belirlenmiştir (Koenning ve ark., 1999).

Dünya'da mısır yetiştirilen alanlarda birçok endoparazit nematodlar tespit edilmesine karşın ülkemizde mısır yetiştiriciliğinin yapıldığı Karadeniz Bölgesi'nde geniş çaplı nematodlara ilgili detaylı bir çalışma yapılmamıştır. Bu alanda Yüksel (1974) ve Elekçioğlu (1992) başta olmak üzere çok az sayıda araştırmacı çalışma yürütmüşlerdir.

Nematodlar tarafından meydana gelen ürün kayıplarının daha iyi anlaşılabilmesi ve bunlarla mücadelede uygun yöntemleri seçmek veya alınacak önlemlere karar verilebilmesi bakımından nematodların yoğunlukları ve populasyon dalgalanmalarına dair bilgilerin ortaya çıkarılması önem arz etmektedir (Pinochet ve ark. 1990; Ma ve ark., 2007). Bu çalışma ile, Ordu ili koşullarında mısır bitkisinin dokuları içerisine giriş yapıp yaşamını burada sürdüren endoparazit olarak bilinen kök-ur ve kök lezyon nematodlarının topraktaki populasyon dalgalanmasının tespit edilerek, mısır yetiştiriciliğinde bu nematodlarından kaynaklı ortaya çıkabilecek problemlere karşı uygun mücadele tavsiyelerinin yapılabilmesine temel oluşturması hedeflenmiştir.

\section{Materyal ve Yöntem}

Çalışmanın ana materyalini, mısır yetiştiriciliği yapılan tarlalardan alınan topraklardan elde edilen kök-ur nematodları (Meloidogyne spp.)'na ait ikinci dönem infektif larvaları (Şekil 8) ile kök lezyon nematodları (Pratylenchus spp.)'na ait larva ve ergin bireyler oluşturmaktadır (Şekil 9).

\section{Toprak örneklenmesi}

Mısır yetiştirilen alanlardaki populasyon dalgalanmalarını saptamak üzere, biri Altınordu (A Tarlası) ilçesinde diğeri Ünye (B Tarlası) ilçesinde bulunan iki farklı mısır tarlası seçilmiştir. Toprak örnekleri, yaklaşık birer aylık aralıklarla alınmıştır. Toprak örnekleri 0-30 cm derinlikten olmak suretiyle araziyi temsil edecek şekilde zig-zak yöntemine göre el küreği yardımıyla alınmıştır. Toprak örnekleri karıştırılarak yaklaşık $1 \mathrm{~kg}$ olacak şekilde alınıp, etiketlenerek, laboratuvara getirilerek, ekstraksiyona tabi tutulana kadar +4 ${ }^{\circ} \mathrm{C}$ 'de buzdolabında muhafaza edilmiştir. 


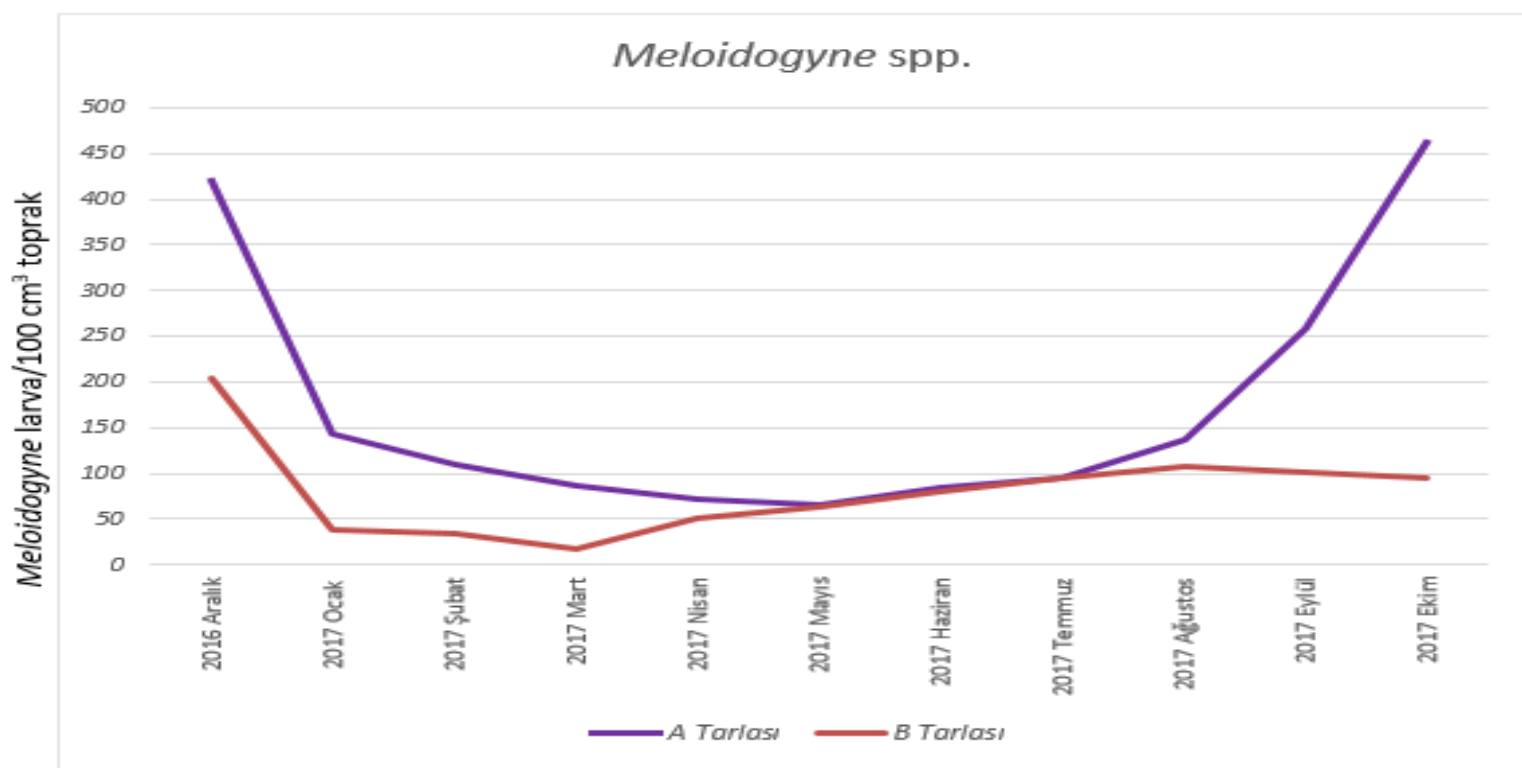

Şekil 1. Kök-ur nematodları (Meloidogyne spp.)’nın A ve B tarlasındaki popülasyonu.

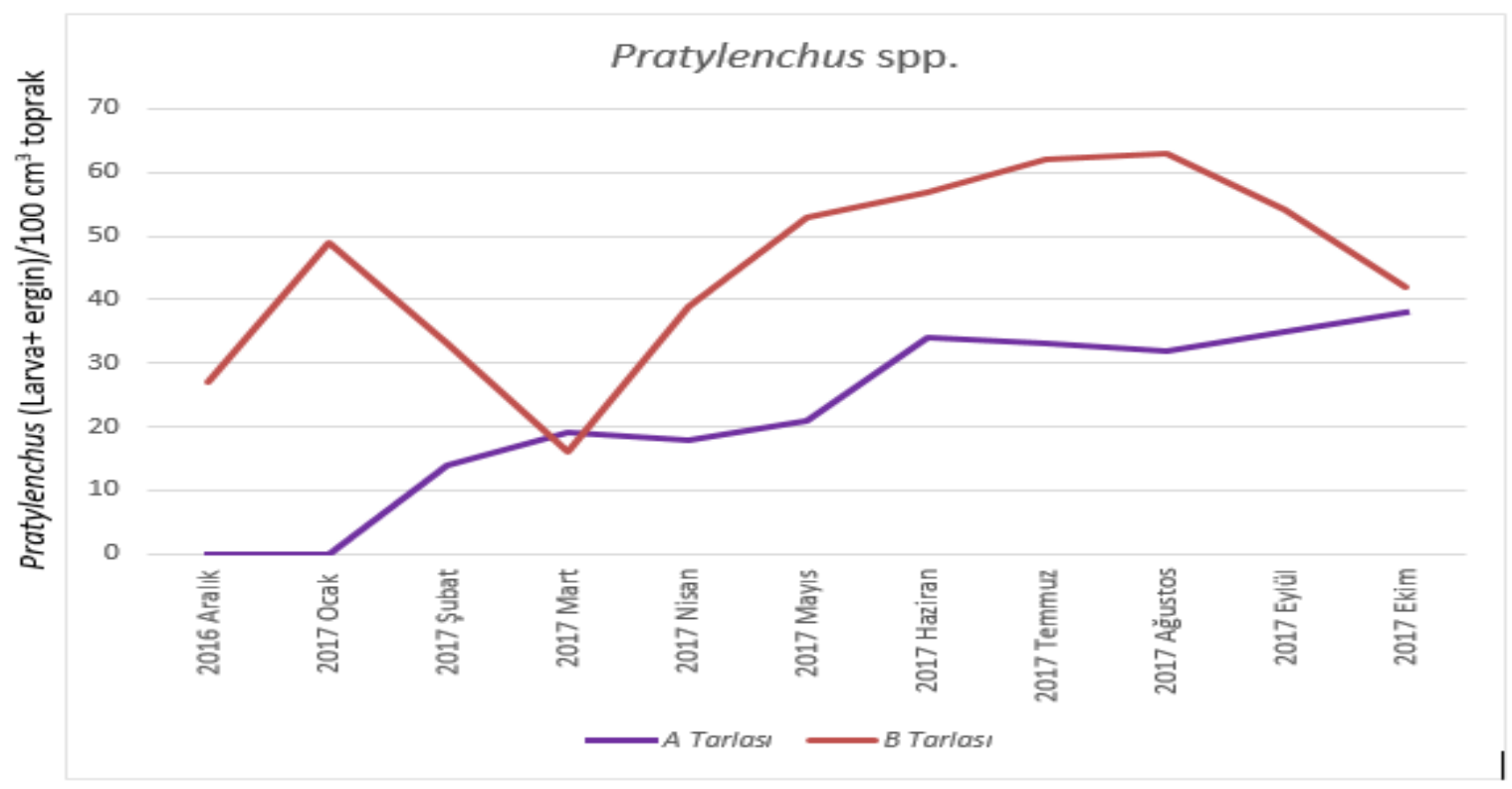

Şekil 2. Kök lezyon nematodları (Pratylenchus spp.)'nın A ve B tarlasındaki popülasyon.

\section{Nematodların ekstraksiyonu}

Laboratuvara getirilen toprak örneklerinden $100 \mathrm{~cm}^{3}$ örnek alınarak Modifiye Baerman tepsi yöntemiyle kök-ur nematodlarına ait 2.dönem larva ve lezyon nematodlarına ait larva ve erginler elde edilmiş (Whitehead ve Hemming, 1965) ve 10 ml'lik ekstraksiyonun tamamı ZEISS marka Inverted ışık mikroskobu altında 200X (10X oküler X 20X objektif) büyütmede sayılmıştır.

Tablo 1. Populasyon takibi yapılan A ve B tarlalarından alınan topraklara ait bazı özellikler.

\begin{tabular}{lccl}
\hline \multirow{2}{*}{ Özellikler } & \multicolumn{2}{c}{ Yer } & \multirow{2}{*}{ Kullanılan Analiz Yöntemi } \\
\cline { 2 - 3 } & A Tarlası (Altınordu) & B Tarlası (Ünye) & \\
\hline Toprak Bünyesi & Killi-Tınlı & Killi & Saturasyon Çamuru \\
Organik madde (\%) & 2.20 & 1.95 & Walkley-Black Yöntemi \\
Potasyum $\left(\mathrm{K}_{2} \mathrm{O}\right)$ & 462 & 149 & Amonyum Asetat yöntemi \\
Fosfor $\left(\mathrm{P}_{2} \mathrm{O}_{5}\right)$ & 3.97 & 2.28 & Bray Kurtz Yöntemi \\
$\mathrm{PH}$ & 7.24 & 7.48 & Saturasyon Çamuru \\
\hline
\end{tabular}




\section{Toprak analizi}

Populasyon takibinin yapıldığı her iki tarladan alınan toprak örneklerinin özelliklerinin belirlenmesi için analiz edilmiştir. Toprakların içermiş oldukları \% organik madde miktarı, toprak reaksiyonu $(\mathrm{pH})$, fosfor $\left(\mathrm{P}_{2} \mathrm{O}_{5}\right)$, potasyum $\left(\mathrm{K}_{2} \mathrm{O}_{5}\right)$ ile toprak bünye yapısı (toprak tekstürü) gibi faktörler farklı yöntemler kullanılarak tahlil edilmiştir (Tablo $1)$.

Topraktan elde edilen nematodların yoğunlukları korelasyon ve regresyon analizleri yapılarak değerlendirilmiştir.

\section{Bulgular ve Tartışma}

Mısır üretiminin yapıldığı topraklarda endoparazit türlerden olan kök ur nematodları (Meloidogyne spp.) ile kök lezyon nematodları (Pratylenchus spp.)'nın mevsime bağlı olarak populasyonlarındaki değişimleri belirlemek amacıyla 2016 yılı Aralık ayından itibaren başlayarak 2017 yılının Ekim ayına kadar populasyon takibi yapılmıştır. Bunun için biri Altınordu (A tarlası) diğeri Ünye ( $B$ tarlası) ilçesinde seçilen iki tarlada bu takip gerçekleştirilmiştir. Kök-ur nematodlarına (Meloidogyne spp.) ait Aralık ayında yapılan ilk incelemede nematod yoğunluğu A tarlası için 421 (Larva/100 $\mathrm{cm}^{3}$ toprak) ve B tarlası için 203 (Larva/100 $\mathrm{cm}^{3}$ toprak) olarak tespit edilmiştir. $\mathrm{Bu}$ aydan sonraki sayımlarda populasyon yoğunluğunun her iki tarlada da birkaç ay boyunca azalarak devam ettiği gözlenmiştir. Populasyondaki bu düşüş B tarlasında mart ayına kadar devam ederken A tarlasında 2017 yılı Mayıs ayına kadar sürmüştür. Her iki tarlada da bu aydan sonra populasyon yoğunluğuna artış gözlenmiş olup $A$ tarlasında aynı yılın Ekim ayında en yüksek yoğunluğa (462 J2/100 $\mathrm{cm}^{3}$ toprak) ulaştığı, B tarlasında ise en yüksek yoğunluğa $\left(108 \mathrm{~J} 2 / 100 \mathrm{~cm}^{3}\right.$ toprak) Ağustos ayında ulaştığı gözlenmiştir. Kök lezyon nematodlar (Pratylenchus spp.)'ında A tarlasında kış sezonunda Aralık ve Ocak ayında toprakta hiçbir nematoda rastlanmazken, Şubat ayından sonra populasyon artış olduğu gözlenmiştir. En yüksek yoğunluk (38 nematod/100 $100 \mathrm{~cm}^{3}$ toprak) ekim ayında rastlanmıştır. B tarlasında ise kış döneminde (Ocak ve Şubat) toprakta nematod yoğunluğuna $\left(27 ; 49\right.$ nematod $/ 100 \mathrm{~cm}^{3}$ toprak) rastlanmış olup, mart ayında yoğunluk düşmüştür. Nisan ayından sonra başlayan artış Ağustos ayına kadar devam etmiş ve bu ayda en yüksek yoğunluk 63 nematod $/ 100 \mathrm{~cm}^{3}$ toprak olarak tespit edilmiştir. Tylka ve ark., (2011), lowa'da mısır yetiştirilen alanlarda ortalama popülasyon yoğunluğunun 21 nematod $/ 100 \mathrm{~cm}^{3}$ toprak olduğunu belirtmişlerdir.

Nematodların üreme ve çoğalmasında önemli faktörlerden biri sıcaklıktır. Özellikle toprak sıcaklığı nematodlarının dağılımını etkileyen en önemli ana abiyotik faktördür (Asiedu ve ark., 2017). Toprak sıcaklığının $10^{\circ} C^{\prime}$ den az olması durumunda nematod yumurta açılmanın inhibe olduğu (Goodell ve Ferris, 1989), sıcaklığın $5^{\circ} C^{\prime}$ nin altına düşmesi durumunda ise larvaların büyük çoğunluğunun (\%75’i) öldüğü belirtilmektedir (Tsai, 2008). Populasyon takibinin yapıldığı her iki tarlanın bulunduğu ilçelerdeki toprak sıcaklık verileri elde edilerek Şekil 3 ve Şekil 4'de verilmiştir. B tarlasındaki hem Pratylenchus spp. yoğunluğu hem de Meloidogyne spp. populasyon yoğunluklarının toprak sıcaklığı arasında pozitif bir ilişkinin olduğu tespit edilmiştir (Şekil 6, Şekil 7). Fakat, A tarlasındaki Pratylenchus spp. populasyon yoğunluğu ile toprak sıcaklığı arasında pozitif bir ilişki olduğu gözlenirken (Şekil 5), Meloidogyne spp. populasyon yoğunluğunun toprak sıcaklığı herhangi bir ilişkili gözlenmemiştir.

Sıcaklık parametresinin yanı sıra, birçok sayıda diğer faktörlerin de nematodlardaki populasyon dalgalanmasına etkileri bulunmaktadır. Toprak ekosistemine bağımlı olarak yaşayan nematodların populasyon takibinde toprak yapısının özelliklerinin belirlenmesinin önemi büyüktür (Taylor ve Sasser, 1978). Gerek kök ur nematodu türleri (Meloidogyne spp)'nin, gerekse kök lezyon nematodu türleri (Pratylenchus spp.)'nin gelişmesinde ve yayılmasında abiyotik faktörler önemli bir rol oynamaktadır. Bu nedenle bu çalışmada, populasyon sayımı yapılan tarlalardan alınan örnekleri tahlil edilerek, toprak tekstürü, organik madde içerikleri, $\mathrm{pH}$ değerleri ile fosfor ve potasyum içerikleri belirlenmiştir. Yapılan analiz sonuçlarına göre $A$ tarlasından alınan toprak yapısal olarak killi-tınlı, B tarlasının toprak bünyesi ise tınlı yapıya sahip olduğu görülmüştür (Tablo 1 ). Toprak tekstürü nematodların ventral ve dikey yayılımlarını etkilediği bilinmektedir (Wallace, 1963). Özellikle Pratylenchus türlerinin yayılımında toprak tekstür yapısı en önemli faktörlerden biridir. Bazı Pratylenchus türlerinin oldukça hafif kumlu topraklarda daha iyi yayılım gösterirken, bazıları killi ve tınlı toprakları sevmektedir (Wallace, 1983). Yapılan çalışmalarda Pratylenchus crenatus ve $P$. penetrans'in esas olarak kumlu topraklarda bulunduğunu, $P$. neglectus'un ise killi ve tınlı topraklarda bulunduğu belirtilmiştir (Loof 1978). Yine Pratylenchus crenatus, Ohio'da killi ve killi-tınlı topraklarda bulunabilirken (Brown ve ark. 1980), Avrupa'da ise hafif kumlu topraklarda bulunmuştur (Florini ve ark. 1987). Benzer şekilde kök-ur nematod türleri için de killi topraklara göre kumsal toprakların daha uygun olduğu belirtilmiştir (Taylor ve Sasser 1978).

Organik madde içerik durumlarına bakıldığında, A ve B tarlasından alınan toprakların analiz sonucunda organik madde miktarı A tarlası 
için \%2.2, B tarlası için \%1.95 olarak tespit edilmiştir. $\mathrm{Bu}$ oranlar toprakların organik madde içerik yönünden değerlendirildiğinde "az" sınıfına girmektedir. Yüksek orandaki organik madde içeriği hafif topraklarda su tutma kapasitesini artırmakta iken, ağır topraklarda toprak yapısını düzeltmektedir. Fakat organik madde toprakta yaşayan nematodlarla rekabet halinde olan canlılar için gerekli olan besin maddelerini sağladığından topraktaki mikrobiyal faaliyeti artırarak bitkileri nematodlara karşı koruduğu bilinmektedir ( Peet, 2008). Topraktaki organik madde içeriği ile Pratylenchus spp. türlerinin sayısı arasında bir ters korelasyon olduğu bir çok araştırmacı tarafından doğrulanmıştır (Muller ve Gooch 1982, Szczygiet ve Zepp 1983). Benzer şekilde organik maddenin toprakta kök ur nematodu populasyonunu ve gal indeksini de azalttığı araştırıcılar tarafından belirtilmiştir (Basile ve ark. 2002; Chandel ve ark. 2002).
Populasyon takibinin yapıldığı tarla topraklarının asitlik durumu incelemesinde her iki tarlanın toprakları nötr özellik ( $\mathrm{A}$ tarlası $\mathrm{pH}=7.24$; $\mathrm{B}$ tarlası $\mathrm{pH}=7.28$ ) gösterdiği tespit edilmiştir. Kök-ur nematodlarının toprakta optimum 4-8 pH değerleri arasında yaşayabildiği bildirilmiştir (Wallace, 1971). Pratylenchus spp'nin topraktaki varlığı toprak $\mathrm{pH}$ bağlı olarak değişebilmektedir. Pratylenchus penetrans esas olarak kumlu ve çok asidik topraklarda bulunabilirken, $P$. neglectus ve $P$. crenatus türleri her türlü toprakta bulunmuştur (Chałańska, ve ark., 2016). Özetle elde edilen sonuçlar, toprak asitliği, toprak dokusu, organik madde, fosfor ve postayum içeriği gibi edafik faktörlerin kök-ur ve kök lezyon nematodlarının populasyon yoğunluğuna etki edecek düzeyde olmadığı tespit edilmiştir. Bu nedenle, uygun toprak koşulları nematod gelişimini destekleyebileceğini göstermektedir.

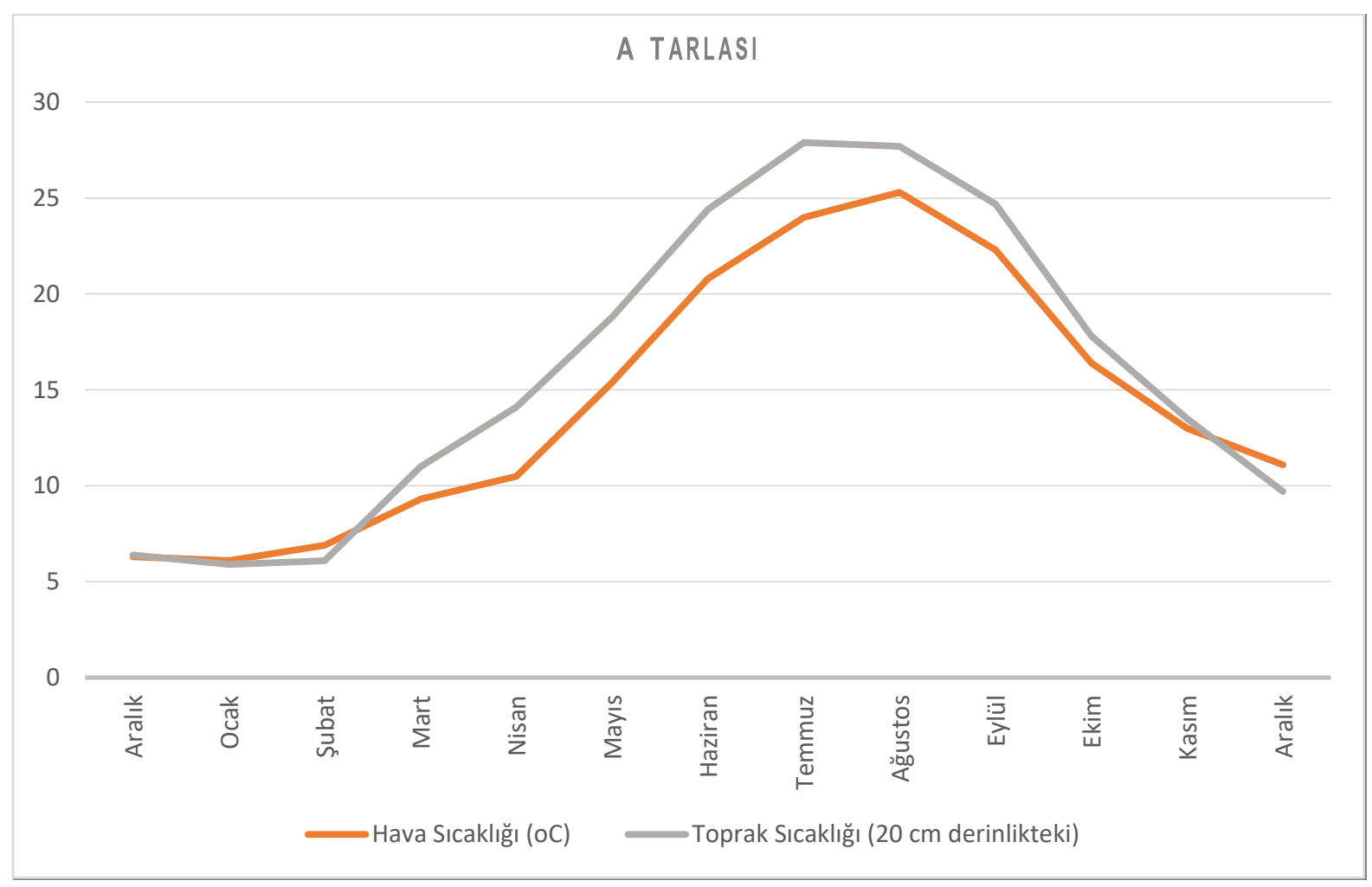

Şekil 3. Populasyon takibinin yapıldığı A tarlasının bulunduğu ilçeye ait aylık iklim verileri. 


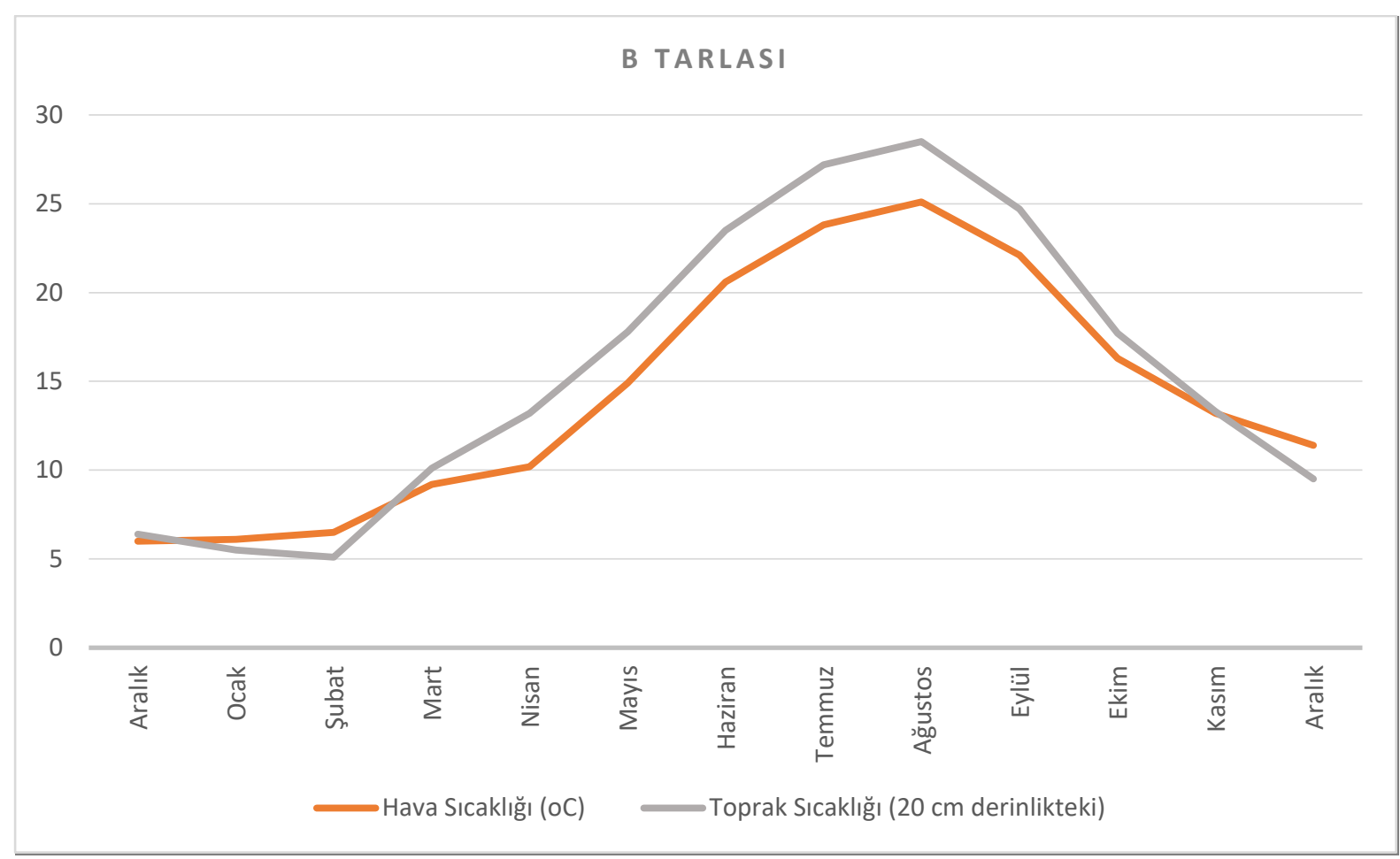

Şekil 4. Populasyon takibinin yapıldığı B tarlasının bulunduğu ilçeye ait aylık iklim verileri.

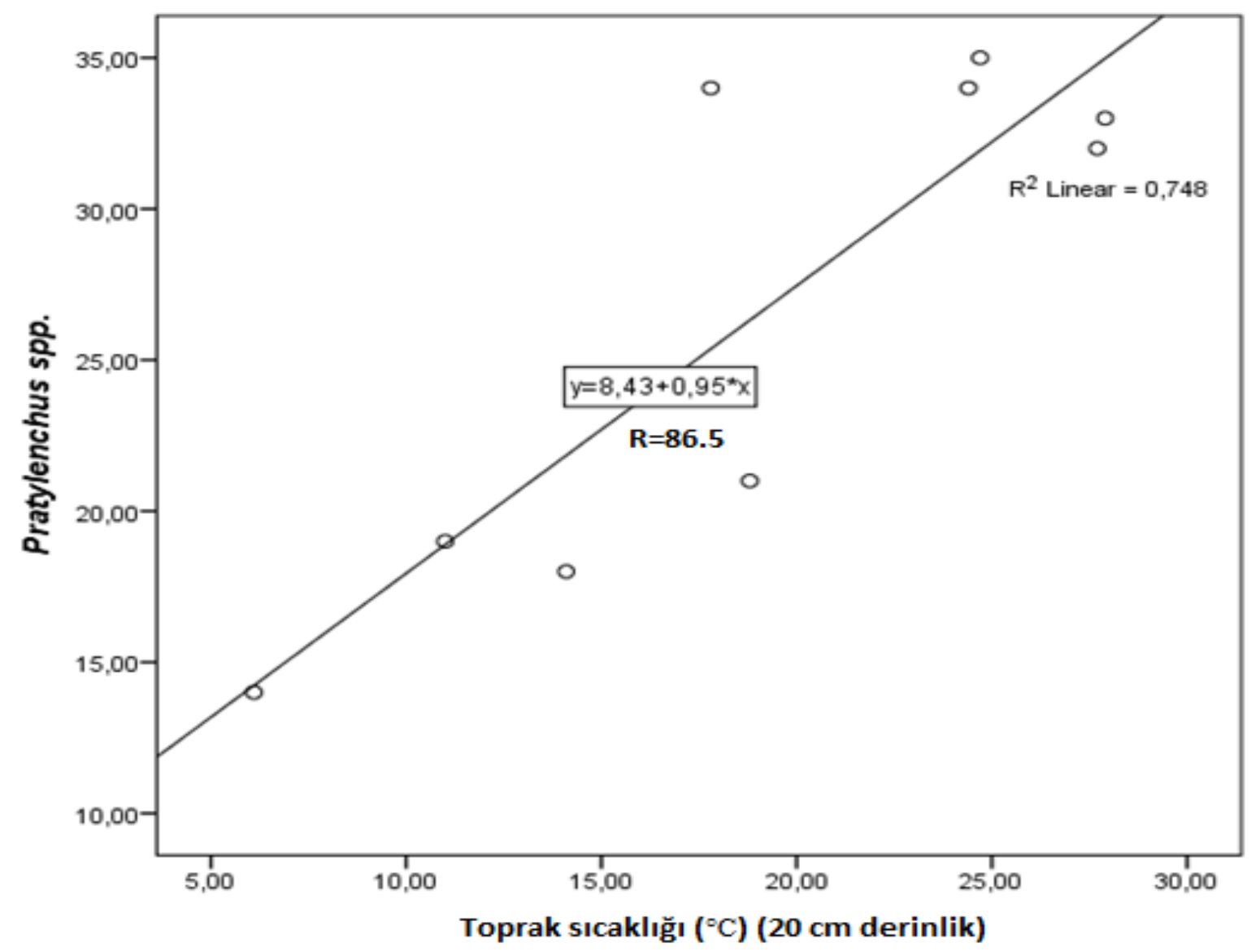

Şekil 5. A tarlasındaki Pratylenchus spp.'nin populasyon yoğunluğu ile $20 \mathrm{~cm}$ derinlikteki aylık ortalama toprak sıcaklığı arasındaki ilişki. 


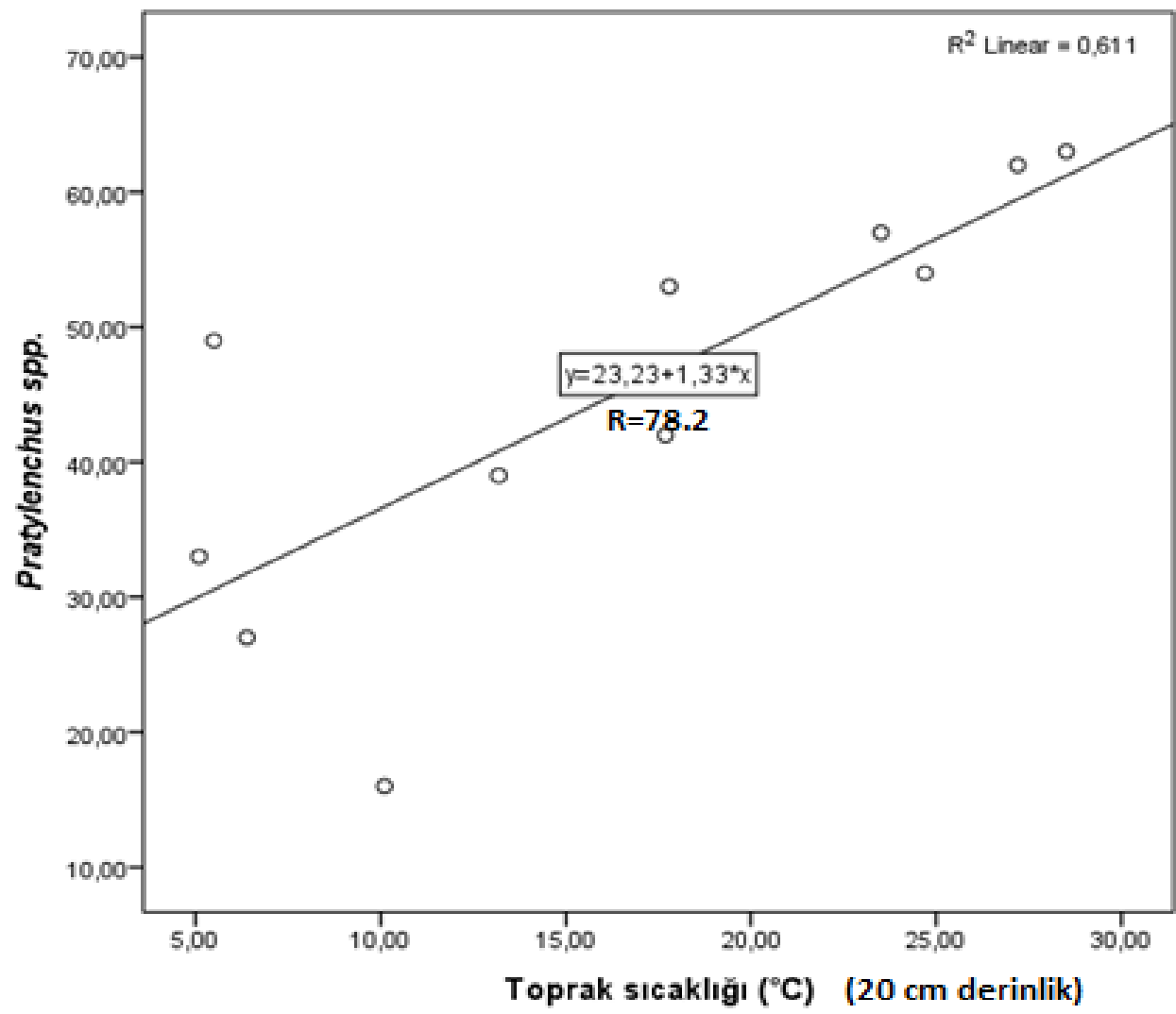

Şekil 6. B tarlasındaki Pratylenchus spp.'nin populasyon yoğunluğu ile $20 \mathrm{~cm}$ derinlikteki aylık ortalama toprak sıcaklığı arasındaki ilişki.

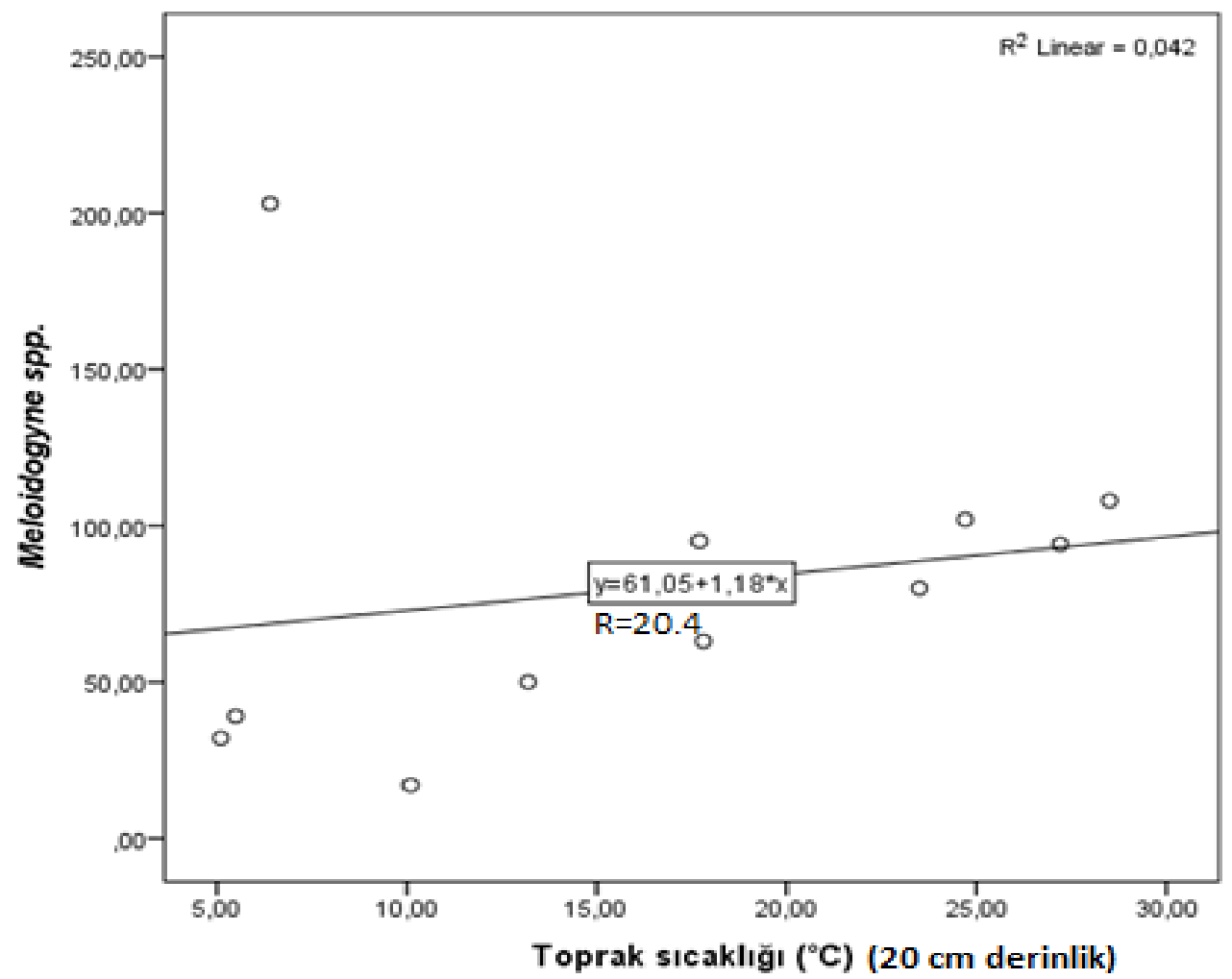

Şekil 7. B tarlasındaki Meloidogyne spp.'nin populasyon yoğunluğu ile $20 \mathrm{~cm}$ derinlikteki aylık ortalama toprak sıcaklığı arasındaki ilişki. 


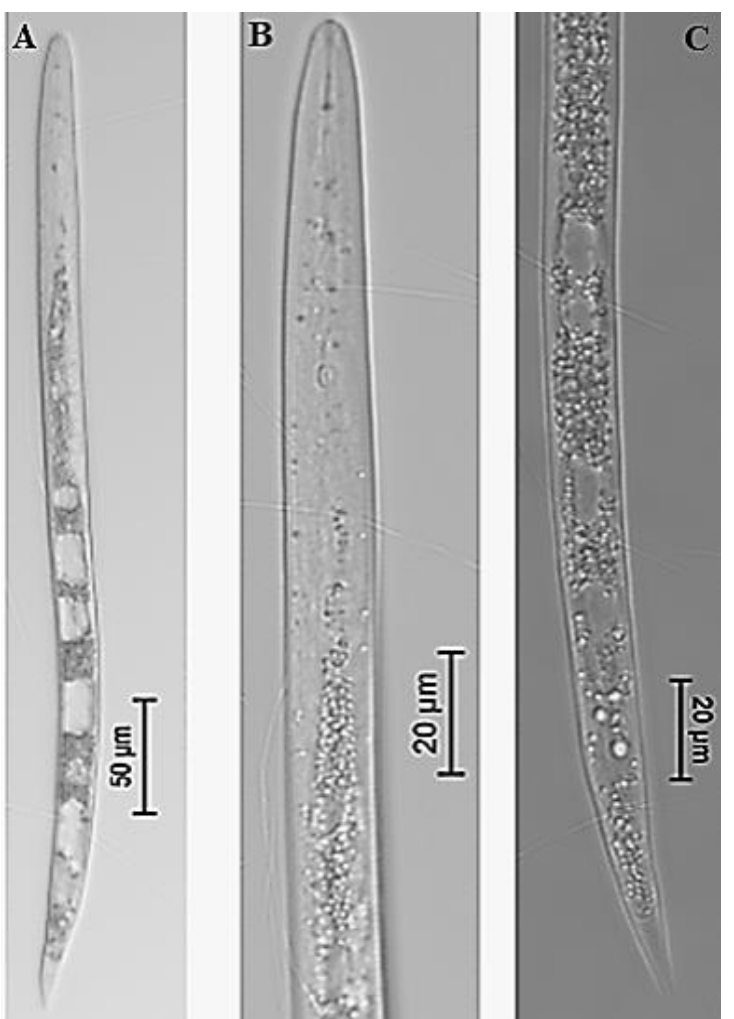

Şekil 8. Kök-ur nematodu Meloidogyne spp'nin ikinci dönem larva'sına ait $A$ : genel görünümü, $B$ : anterior, C: posterior bölgesinin görünümü.

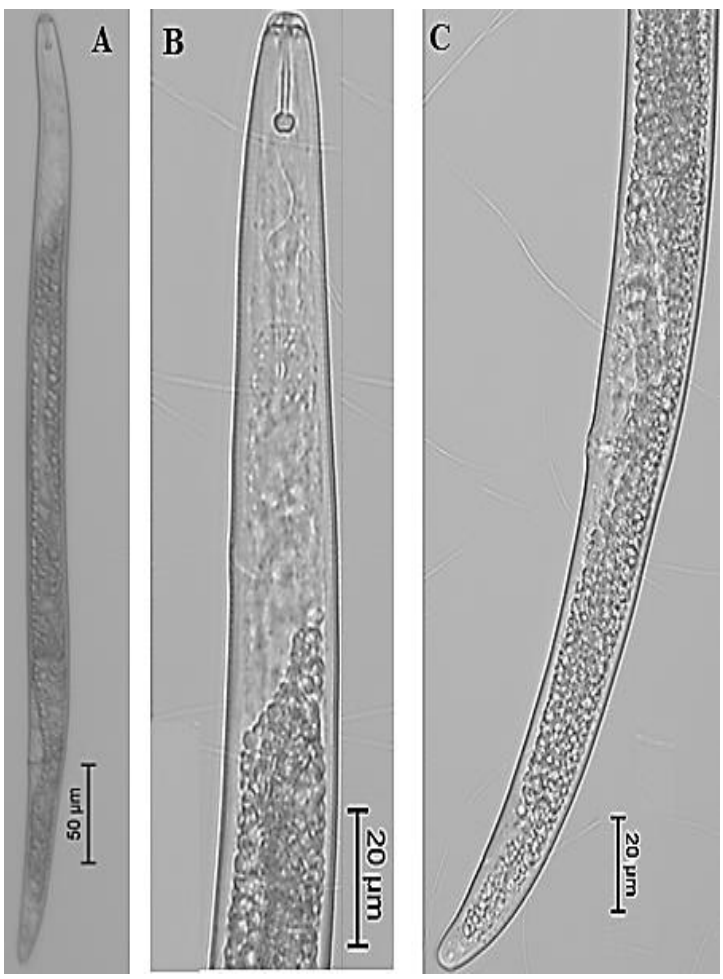

Şekil 9. Kök lezyon nematodu Pratylenchus spp’nin dişisine ait $A$ : genel görünümü, $B$ : anterior, $C$ : posterior bölgesinin görünümü.

\section{Sonuç ve Öneriler}

Bu çalışma sonucunda Ordu ilinde Altınordu ve Ünye ilçelerinde bulunan iki ayrı mısır tarlasında, yıl boyunca kök-ur nematodu Meloidogyne spp. türleri ile kök lezyon nematodu Pratylenchus spp. türlerinin mevsime bağlı olarak populasyon dalgalanması izlenmiştir. Genel olarak toprak sıcaklığına bağlı olarak yılın belirli dönemlerinde popülasyonda artışlar oluğu gözlenmiştir. Çalışma sonuçlarından elde edilen veriler, Ordu ili mısır yetiştiriciliği yapılan toprakların sahip olduğu $\mathrm{pH}$, toprak tekstürü, organik madde miktarı, fosfor ve potasyum içerikleri kök ur nematodları (Meloidogyne spp.) ve kök lezyon nematodları (Pratylenchus spp.) için olumsuz etkide bulunacak özellikleri taşımadığını göstermiştir. Yalnızca toprak sıcaklığının pozitif yönde nematod yoğunluğunu etkilediği ortaya çıkmıştır. Bu çalışmanın, bitkilerde nematodlar tarafından kaynaklanan verim kayıplarının daha iyi anlaşılarak mücadeleye başlama zamanının belirlenmesinde, ortamda bulunan nematodların populasyon yoğunluk ve değişimlerine dair bilgiler üreticilere katkı sağlayacağı düşünülmektir.

¥: Bu çalışma, Ordu üniversitesi Bilimsel Araştırmalar Birimi (BAP) tarafından desteklenen (Proje No: BY-1714) Yüksek lisans tez çalışmasının bir kısmıdır.

\section{Kaynaklar}

Anonim, 2005.

http://dspace.trakya.edu.tr:8080/jspui/bitstream/ 1/80/1/Babao \%C4\%9Flu\%20. Metin.pdf.

Asiedu, O., Kwoseh, C.K., Melakeberhan, H., Gyapong, T.A. 2017. Nematode distribution in cultivated and undisturbed soils of Guinea Savannah and Semi-deciduous Forest zones of Ghana. Geoscience Frontiers, 1-7.

Basile, M., D'Addabbo, T., Candido, V., Sabino, G., Gatta, G., Mele, G., Miccolis, V. 2002. Soil solarization and organic matter synergism against Meloidogyne javanica in greenhouse. Italus Hortus, 9(6): 96-100.

Brown, M.J., Riedel, R.M., Rowe, R.C. 1980. Species of Pratylenchus associated with Solanum tuberosum cv. Superior in Ohio. Journal of Nematology, 12: 189-192.

Chałańska, A., Łabanowski, G., Sas, D. 2016. Rootlesion nematodes (Pratylenchus spp.) in ornamental plant nurseries - influence of soil texture, acidity, salinity and organic matter content. Communications in Biometry and Crop Science, 11: 98-104.

Chandel, S.T., Gaur, H.S., Alam, M.M. 2002. Population dynamics of the root-knot nematode Meloidogyne triticoryzae under five rice-based cropping systems. Archives of 
Phytopathology and Plant Protection, 35(1): 43-51(9).

Elekçioğlu, i. H., 1992. Untersuchungen zum Auftreten und zur Verbreitung phytoparasitärer Nematoden in den landwirtschaftlichen Hauptkulturen des ostmediterranen Gebietes der Türkei. (Doğu Akdeniz Bölgesi önemli kültür bitkilerindeki nematode türleri ve bölgedeki dağılışları üzerine araştırmalar) Plits, 10(5): 120.

Florini, D.A., Lorai, R., Kotcon, J.B. 1987. Influence of edaphic factors and previous crop on Pratylenchus spp. Population densities in potatoes. Journal of Nematology, 19: 85-92.

Goodell, P.B., Ferris, H. 1989. Influence of Environmental Factors on the Hatch and Survival of Meloidogyne incognita. Journal of Nematology, 21(3): 328-334.

Koenning, S.R., Overstreet, C., Noling, J.W., Donald, P.A., Becker, J.O., Fortnum, B.A. 1999. Survey of crop losses in response to phytoparasitic nematodes in the United States for 1994. Journal of Nematology, 31(4S): 587.

Kün, E., Emekliler, Y. 1987. İklim faktörleri bakımından Türkiye'de mısır üretim olanakları. Türkiye'de Mısır Üretiminin Geliştirilmesi, Problemler ve Çözüm Yolları Sempozyumu, 86-124.

Loof, P. A. A. 1978. The genus Pratylenchus Filipjev, 1936 (Nematoda : Pratylenchidae) : A review of its anatomy, morphology, distribution, systematics and identification. Vuxtskyddsrapporter, 5, $50 \mathrm{p}$.

Ma, K.C., Jo, Y.S., Kim, B.H., Lim, D.G. 2007. Seasonal occurrence and aspects of root-knot nematodes in major kiwifruit cultivation areas of Korea. 753: VI International Symposium on Kiwifruit, Rotorua (New Zealand), Acta Horticulturae (ISHS), 753: 719-724.

Muller R., ve Gooch P.S. 1982. Organic amendments in nematode control. An examination of the literature. Nematropica 12, 319-326.

Norton, D.C. 1983. Maize nematode problems. Plant Disease, 67(3): 253.

Oerke, E.C., Dehwe, H.W., Schönbeck, E., Weber, A. 1994. Crop Production and Crop
Protection. Estimated Losses in Major Food and Cash Crops. Elsevier, Amsterdam.

Peet, M., 2008. Nematode Management. (http://www.cals.ncsu.edu/).

Pinochet, J, Verdejo, S., Soler, A. 1990. Observations on the seasonal fluctuation of Meloidogyne hapla on kiwi (Actinidia deliosa) in Spain. Nematropica, 20: 31-37.

Szczygieł, A., Zepp, A. 1983. Effect of organic matter in soil on population and pathogenicity of Pratylenchus penetrans and Longidorus elongatus to strawberry plants. Zeszyty Problemowe Postępów Nauk Rolniczych 278: 113-122.

Taylor, A.L., Sasser, N. 1978. Biology, Identification and Control of Root-Knot Nematodes. Raleigh; N.C. State Univ., 111 p.

Thorne, G., 1961. Principles of Nematology. Mc Graw-Hill Book Company, Inc. Newyork, Toronto, London.

Tsai, B.Y. 2008. Effect of temperature on the survival of Meloidogyne incognita. Plant Pathology Bulletin, 17: 203-208.

Tylka, G.L., Sisson, A.J., Jesse, L.C., Kennicker, J., Marett, C.C. 2011. Testing for plant-parasitic nematodes that feed on corn in lowa 20002010. Plant Health Progress, doi:10.1094/PHP-2011-1205-01-RS.

Wallace, H.R. 1963. The Biology of Plant Parasitic Nematodes. The Biology of Plant Parasitic Nematodes. 288 pp.

Wallace, W.L. 1971. The Logic of Science in Sociology. American Journal of Sociology. Search Journal.

Wallace, H.R. 1983. Interactions between nematodes and other factors of plants. Journal of Nematology 15: 221-227.

Whitehead, A.G., Hemming, J.R. 1965. A comparison of some quantitative methods of extracting small vermiform nematodes from soil. Annuals of Applied Biology, 55: 25-38.

Yüksel, H.Ş. 1974. Doğu Anadolu'da tespit edilen Pratylenchus türlerinin dağılışı ve bunlar üzerinde sistematik çalışmalar. Atatürk Üniversitesi Ziraat Fakültesi Ziraat Dergisi, 4: 53-71. 